Such characteristics are not conducive to men developing the necessary knowledge and skills for a fulfilling sex life. How does a young man learn what to do apart from put on a condom and plug in his genitals? Asking others directly for information is an embarrassing admission that he does not know something every man should know. Learning from a potential partner also presents difficulties because men feel under pressure to be the initiators and leaders in sexual activity. Leading in ignorance arouses anxiety and contributes to poor physical performance.

The fear and inability to discuss sex frequently continue into longstanding relationships, and intercourse remains something that is done, not discussed. Silence should not imply contentment. How does a man know if he is a good lover or how he compares with her previous partners, or what she likes and dislikes in physical intimacy, without any verbal communication? Unsatisfying routines all too easily become established. The inability of a man to meet his sexual needs in a relationship dulls emotional feelings towards the partner, reduces his interest in sex in that relationship, and enhances his vulnerability to accept sexual stimulation elsewhere. Casual sexual encounters or affairs may be followed by deep self loathing and guilt, which may interfere with subsequent sexual relationships.

Media models are distinctly unhelpful to men struggling with sex. Foreplay is rarely depicted, and penetrative performance is vigorous, enduring, and associated with ecstasy. Women are still all too often portrayed as accessories to be used, the property and playthings of men and "call girls of convenience." Expressions of reluctance to have sex are treated as a social game: resistance is to be overcome with force, and masculinity proved.

What if the genital apparatus does not perform? Self esteem plummets, self anger and self recrimination rage. Intimacy becomes a time of acute anxiety to be avoided. Embarrassment and poor communication skills generally preclude early discussion of difficulties. A powerful conviction develops that something is wrong with the penis, although the core problem is usually cerebral or with the relationship. Help is possible after the problem has been acknowledged and disclosed, although the demand for practitioners with psychosexual skills outstrips the supply.

Recent surveys of lifestyle have provided contemporary data on a few aspects of male sexual behaviour and concur that most men are not highly promiscuous and few are homosexual. ${ }^{34}$ Sexual health needs viewing in broader terms than the incidence of new sexual partners, sexually transmitted infections, and teenage pregnancy. Improving the sexual health of the nation requires more than condoms. Male-male friendship needs revisiting, to help personal communication skills and the expression of feelings. What is not needed is any "new man," a fantasy image that denies integral facets of masculinity. Unrealistic expectations need allaying by more open communication and the depiction of more realistic male role models. Sex educators need confidence to enlarge their brief from the physiological to include intimacy, psychological factors, and morals. We all hold moral values, and being non-judgmental does not preclude discussion of them. More open discussion on how and why men behave as they do will implicitly involve women and cannot but improve the sexual health of all.

CHRISTOPHER BIGNELI

Department of Genitourinary Medicine, Consultant in genitourinary medicine

Nottingham City Hospital,

Nottingham NG5 1PB

1 Zilbergeld B. Men and sex. London: Fontana, 1980:11-5.

2 Moir A, Jessel D. Brain sex. London: Mandarin, 1991

3 Johnson AM, Wadsworth J, Wellings K, Bradshaw S, Field J. Sexual lifestyles and HIV risk. Nature 1992;360:410-2.

Mapping and sexual lifestyles. Lancet 1992;340:1441-2.

\title{
Psychological consequences of screening for Down's syndrome
}

\section{Still being given too little attention}

The sophistication of screening for Down's syndrome has grown rapidly in the past few years, but the development of any test is only the first step along the road to a clinical service. To meet the objectives of prenatal testing for fetal abnormalities, ${ }^{12}$ health professionals must ensure that parents make informed decisions about having an initial screening test and any subsequent diagnostic tests and, in a few cases, about whether to keep on with or terminate an affected pregnancy. Moreover, with any screening test there is a particular need to "first do no harm." ${ }^{3}$ These requirements have sometimes been overlooked in the recent rush to implement screening programmes for Down's syndrome.

Failure to consider these requirements when implementing other prenatal screening tests has led to uninformed decision making, raised anxiety, and false reassurance. ${ }^{4}$ In this week's journal Statham and Green report on the problems encountered by women receiving positive test results ( $p 174) .{ }^{5}$ Similar difficulties have been well documented for over 10 years in women having other prenatal screening tests..$^{6-10}$ Sadly, such problems are still encountered, which raises several questions: why do these problems occur; what have been the obstacles to their prevention; and what can be done to overcome them?
Some of the distress that women experience is attributable to positive test results on prenatal screening and to termination because of a fetal abnormality in a wanted pregnancy. Some women receiving false positive screening results remain anxious even after the birth of an unaffected child. ${ }^{11}$ Distress is very high in the vast majority receiving a positive diagnosis ${ }^{8}$; of those who undergo termination, at least a quarter are significantly distressed two years later. ${ }^{12}$

Aspects of the care that women receive both at the time of testing and when deciding whether to continue with the pregnancy may affect the level of distress. These include the information given at each stage of screening and the level of emotional support. Despite guidelines on prenatal testing women are not always aware of what tests they have undergone or what the results mean. One reason for this is the paucity of information provided by obstetricians and midwives in offering the tests routinely..$^{13}$ Emotional support may be inadequate because some obstetricians and midwives have difficulties in helping parents with the painful decisions that follow a positive test result. ${ }^{14}$

Given our knowledge of the problems for those receiving positive results on prenatal testing for fetal abnormalities, why has so little been done to tackle them? The failure of 
research findings to change clinical practice is an increasingly recognised phenomenon and is not confined to prenatal screening. ${ }^{1516}$ Part of the answer may lie in the lack of feedback staff receive from their patients. Some women seek help outside the health service, contacting agencies such as Support After Termination for Fetal Abnormality (SATFA), the Down's Syndrome Association, and the Royal College of Obstetricians and Gynaecologists. After Down's syndrome is diagnosed most women opt to terminate their pregnancies. They therefore cease being under the care of antenatal staff, who consequently may remain ignorant of their unmet needs.

What should be done? Detailed specifications for good services exist. ${ }^{17} 18$ They emphasise the importance of training and supporting professional staff to allow them to counsel women appropriately. There is, however, little empirically based work to guide practice in this area. There is a need, for example, to evaluate the effectiveness of different approaches to providing care so as to reduce distress and to maximise adjustment and satisfaction with decisions about continuing or interrupting pregnancies. Are better outcomes achieved by training antenatal clinic staff to counsel or by including a trained counsellor as part of the care team? Only with answers to questions like this can we select the best way of caring for the growing number of couples who will face the pain of a diagnosis of a fetal abnormality.

Purchasers hold one of the keys to improving services. They could stipulate in contracts for prenatal screening services that clinical teams providing the screening are trained to provide information and emotional support at all stages of screening and diagnosis. Clinical audit of prenatal screening programmes needs to include assessment both of women's satisfaction with the service and of psychological outcomes, particularly among those recalled on testing. No matter how good a test is technically, screening of uninformed, unsupported patients by unprepared staff is a recipe for at best confusion and at worst great distress. And it is avoidable.

THERESA M MARTEAU Director

Psychology and Genetics Research Group,

United Medical and Dental Schools of

Guy's and St Thomas's,

London SE1 9RT

1 Working Group on the Screening for Neural Tube Defects. Report. London: Department of Health and Social Security, 1979. (D Black, chairman.)

Royal College of Physicians. Prenatal diagnosis and genetic screening: community and servic implications. London: Royal College of Physicians, 1989.

3 Holland WW. Screening: reasons to be cautious. BMJ 1993;306:1222-3.

4 Marteau TM, Slack J. Psychological implications of prenatal diagnosis for patients and health professionals. In: Brock DJH, Rodeck CH, Ferguson-Smith M, eds. Prenatal diagnosis and screening. London: Churchill Livingstone, 1992:663-73.

5 Statham H, Green J. Serum screening for Down's syndrome: some women's experiences. $B M \mathcal{F}$ 1993;307:174-6.

Farrant $\mathrm{W}$. Stress after amniocentesis for high serum alpha-fetoprotein concentrations. $B M \mathfrak{I}$ 1980;281:452.

Griffiths MD, Gough MH. Dilemmas after ultrasonic diagnosis of fetal abnormality. Lancet 1985;i:623-4.

8 Lloyd J, Laurence KM. Sequelae and support after termination of pregnancy for fetal malformation. $B M$ 1 $^{1985 ; 290: 907-9}$.

9 Black RB. A 1 and 6 month follow-up of prenatal diagnosis patients who lost pregnancies. Prenatal Diagnosis 1989;9:795-804.

10 Iles S. The loss of early pregnancy. Bailliere's Clin Obstet Gynaecol 1989;3:769-90.

11 Marteau TM, Cook R, Kidd J, Michie S, Johnston M, Slack J, et al. Psychological effects of false positive results in prenatal screening for fetal abnormality: a prospective study. Prenate Diagnosis 1992;12:205-14.

12 White-van Mourik MAA, Connor JM, Ferguson-Smith MA. The psychosocial sequelae of a second-trimester termination of pregnancy for fetal abnormality. Prenatal Diagnosis 1992;12: 189-204.

13 Marteau TM, Slack J, Kidd J, Shaw RW. Presenting a routine screening test in antenatal care: practice observed. Public Health 1992;106:1311-41.

Whelton JM Sharing the dilemmas: midwives' Professional Nurse 1990; July:514-8.

15 House of Lords Select Committee on Science and Technology. Priorities in medical research. London: HMSO, 1988.

16 Peckham M. Research and development for the National Health Service. Lancet 1991;338:367-71.

17 Drife JO, Donnae D, eds. Antenatal diagnosis of fetal abnormalities. London: Springer-Verlag, 1991.

18 Royal College of Obstetricians and Gynaecologists. Report of the working party on serum screening for Down's syndrome. London: RCOG, 1993.

\title{
No escape: HIV transmission in jail
}

\author{
Prisons need protocols for HIV outbreaks
}

Her Majesty's prison services offer all inmates HIV education and counselling and have a research strategy to establish the prevalence of risk behaviour and of HIV infection among inmates. Some prisons offer condoms to prisoners who are being released and provide drug rehabilitation programmes. ${ }^{1}$ Current measures did not, however, prevent the recent outbreak of hepatitis B and HIV transmissions in a Scottish jail (p 151). ${ }^{2 a}$ The prison services have achieved much in their fight against HIV transmission but there are political and legal barriers to further progress. Urgently needed is a public health protocol that can be implemented when HIV transmission occurs in a jail. This protocol must guarantee prisoners the right to medical confidentiality while ensuring that accurate epidemiological information is collected.

The prison services have worked hard to educate inmates to avoid HIV infection but, unlike other citizens, prisoners are denied condoms and cannot disinfect any needle that they might use. Nearly half of Edinburgh's adult injector inmates had injected during incarceration ${ }^{34}$; one sixth of 16-20 year olds in October 1992 in Polmont, Scotland's largest male young offenders' institution, were injectors, of whom a quarter had injected during their prison terms. ${ }^{5}$ Outside prison, needle exchanges are well established and it is the possession of prohibited injectable substances, not the actual injecting, that breaks the law. A prison sentence, prohibiting access to clean needles for injectors, may become a death sentence. If politicians had the humanity to grant prisoners the same rights to reduce their risk of HIV infection as the rest of the population then prison services could help inmates to stop endangering each other, and they could deliver those rights without risking disorder in the prisons. Practical initiatives are impeded for lack of political will and legal reform.

The prison services' second achievement is to have encouraged officer volunteers to train as HIV counsellors so that confidential, personal HIV testing is available to inmates. Only the Scottish Prison Service has published relevant performance data ${ }^{6}$ Prisoners are unlikely to come forward for testing if they doubt the confidentiality of the results or the medical and social support for HIV infected prisoners. We have reported notably increased uptake of confidential named HIV testing by inmates in temporal association with voluntary anonymous HIV surveillance in prisons. ${ }^{57}$

Prison services in the United Kindom have embraced 